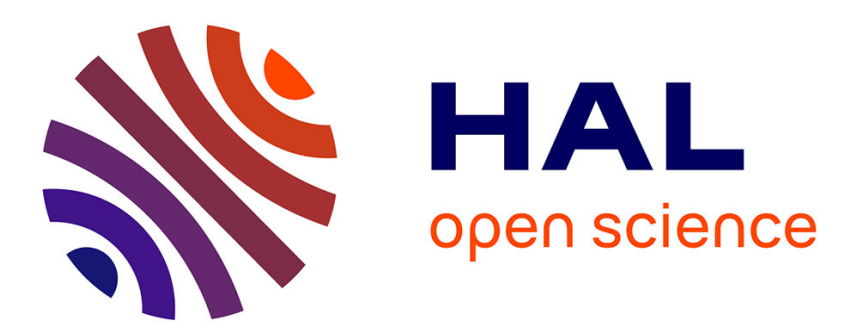

\title{
A Half-Cut Compact Monopole Antenna for SFCW Radar-Based Concrete Wall Monitoring With a Passive Cooperative Target
}

Jiyu Guo, Weike Feng, Jean Friedt, Qing Zhao, Motoyuki Sato

\section{- To cite this version:}

Jiyu Guo, Weike Feng, Jean Friedt, Qing Zhao, Motoyuki Sato. A Half-Cut Compact Monopole Antenna for SFCW Radar-Based Concrete Wall Monitoring With a Passive Cooperative Target. IEEE Geoscience and Remote Sensing Letters, 2019, pp.5. hal-02867718

\section{HAL Id: hal-02867718 https://hal.science/hal-02867718}

Submitted on 15 Jun 2020

HAL is a multi-disciplinary open access archive for the deposit and dissemination of scientific research documents, whether they are published or not. The documents may come from teaching and research institutions in France or abroad, or from public or private research centers.
L'archive ouverte pluridisciplinaire HAL, est destinée au dépôt et à la diffusion de documents scientifiques de niveau recherche, publiés ou non, émanant des établissements d'enseignement et de recherche français ou étrangers, des laboratoires publics ou privés. 


\title{
A half-cut compact monopole antenna for SFCW radar based concrete wall monitoring with a passive cooperative target
}

\author{
Jiyu Guo, Student Member, IEEE, Weike Feng, Student Member, IEEE, Jean-Michel Friedt, Qing Zhao, \\ and Motoyuki Sato, Fellow, IEEE
}

\begin{abstract}
Stepped frequency continuous wave (SFCW) based radar with passive cooperative target is a promising nondestructive method to monitor the concrete temperature change. By burying a Surface Acoustic Wave (SAW) sensor in the concrete to act as the cooperative target, physical properties of the concrete can be measured by analyzing the reflections of the probing SFCW signal. Since the SAW sensor should be connected to an antenna to convert the electromagnetic wave into the acoustic wave, a half-cut compact monopole antenna is designed and fabricated in this letter. Taking the advantages of corrugated edge and half-structure technologies, the size of the monopole antenna decreases significantly without sacrificing the performance, which makes the SAW sensor together with antenna suitable to be inserted into the concrete. Experimental results show that the proposed antenna can work well with the SAW sensor in the concrete and the proposed method can measure the temperature change of concrete continuously.
\end{abstract}

Index Terms - concrete monitoring, SFCW radar, cooperative target, SAW sensor, compact monopole antenna.

\section{INTRODUCTION}

$\mathrm{C}$ ONCRETE is a fundamental material for many types of infrastructure, such as bridges and buildings. Monitoring the properties of a concrete structure and inspecting damaged part of an aged structure are of great importance for people's safety and convenience. Since most of the important properties of concrete are directly or indirectly related to its compressive strength, knowing the rate of strength development at the early age of concrete is critical to the construction-related activities [1]. One approach commonly used for monitoring the strength of concrete is to measure its temperature as a function of time. The temperature is then integrated into some classical methods to predict the concrete strength [2]. Additionally, monitoring the temperature provides not only crucial information about the hardening and setting process of the cement, but also the progress of deterioration mechanisms [3]. Thus, a reliable system for continuously monitoring the concrete temperature change is desirable during construction and afterwards.

Jiyu Guo and Qing Zhao are with University of Electronic Science and Technology of China, Chengdu, China (e-mail:guojiyu282@gmail.com ).

Weike Feng is with the Graduate School of Environmental Studies, Tohoku University, 980-8579, Sendai, Japan (e-mail: feng.weike.q4@dc.tohoku.ac.jp). Jean-Michel Friedt is with the FEMTO-ST, Time \& Frequency department, Besancon, France. (e-mail: jean-michel.friedt@femto-st.fr).

Motoyuki Sato is with the Center for Northeast Asian Studies, Tohoku University, 980-8576, Sendai, Japan (e-mail: motoyuki.sato.b3@ tohoku.ac.jp).
Compared to the conventional destructive testing methods, nondestructive evaluation (NDE) techniques are much cheaper and time saving. They have been widely used over the past two decades to monitor the strength of fresh concrete. Most of these techniques are based on the analysis of linear bulk ultrasonic waves propagating through the concrete [4-5]. One drawback of these techniques is that the sensors/transducers should be close to the inspected object. Another promising technique is using the microelectromechanical system to measure the inner state of concrete [6-7]. The packed sensor, e.g., piezoelectric sensor or temperature sensor, is inserted into concrete and used to obtain the information such as strength gain, temperature, and internal humidity. However, most of these sensors require external power supplies and if the power supply is cut off or the battery is run over, the sensor cannot work anymore.

Since challenges still exist in the measurement of concrete temperature, stepped frequency continuous wave (SFCW) based ground penetrating radar (GPR) seems to be an effective technique to monitor the concrete temperature continuously. As a well-known effective tool for subsurface exploration, GPR works by transmitting electromagnetic waves into the subsurface and receiving the reflected waves to acquire various information of the subsurface feature. The depth, size, shape and other parameters of the subsurface reflectors can be derived [8]. More related, GPR has been used to detect the reinforcing steel bar of the concrete wall in recent years [9]. However, the temperature of the concrete cannot be directly measured by the GPR technique. To solve this problem, a wireless and passive (no power supply needed) sensor designed by surface acoustic wave (SAW) delay lines [10-12] is used as the cooperative target. Since the piezoelectric substrate of the SAW sensor will convert an incoming electromagnetic signal into an acoustic signal whose velocity depends on the temperature of transducer, the phase of the echoes of the SAW sensor will be changed by the temperature variation of the concrete. Therefore, as shown by [13-14], by exploiting the phase information of the SAW sensor detected by the GPR system, an interferometric process can be used to estimate the temperature change.

As indicated by [11], the SAW sensor should be connected to an antenna to convert the electromagnetic wave into an acoustic wave by polarizing the piezoelectric substrate. To make the size of the SAW sensor together with the antenna small enough to be buried inside the concrete, a half-cut compact monopole 
antenna is designed and fabricated in this letter. By utilizing corrugated edge and half structure technologies, the size of monopole antenna decrease significantly to $27 \mathrm{~mm} \times 5.5 \mathrm{~mm} \times$ $1.5 \mathrm{~mm}$ without sacrificing the antenna performance, which makes the cooperative target suitable to be inserted into the concrete without damaging the concrete structure.

The rest part of this paper is organized as follows. Section II presents the principle of the concrete monitoring method by SFCW radar and passive cooperative target. The design of the proposed compact monopole antenna is discussed in Section III. Experiment results are presented in Section IV. Finally, the conclusion is given in Section V.

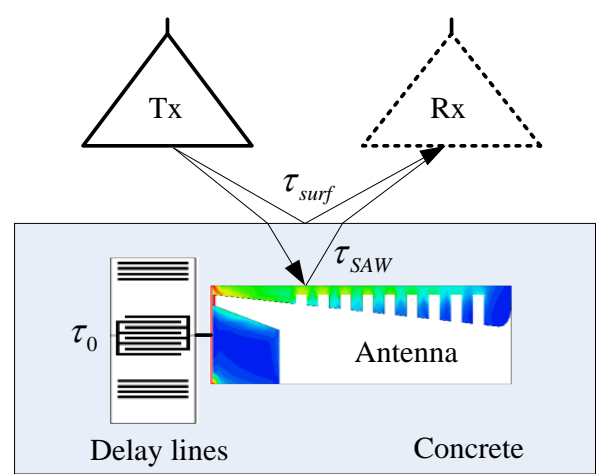

Fig. 1. System geometry of SFCW radar based concrete monitoring.

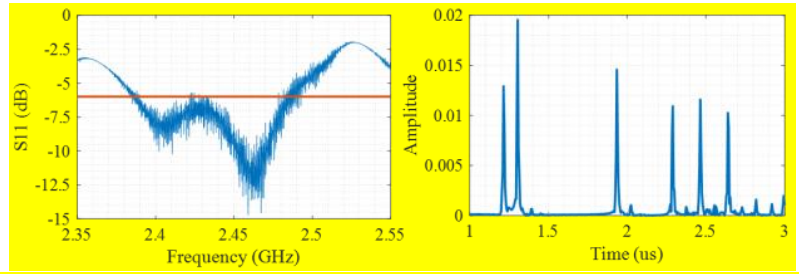

Fig. 2. Frequency domain (left) and time domain (right) reflection coefficient of the SAW sensor.

\section{RADAR BASED CONCRETE MONITORING}

The geometry of the designed radar system for concrete monitoring is shown in Fig. 1. The transceiver is connected to a vector network analyzer (VNA) to generate an SFCW signal from 2.35 to $2.55 \mathrm{GHz}$ with 1601 frequency steps. The SAW sensor will convert the incoming electromagnetic signal into acoustic signals with time delays $\tau_{\mathrm{p}}$, where $p=1,2, \ldots, P$ is the index and $P$ is the number of reflectors. As the sensor is buried close to the surface, the actual delays of the concrete surface and the sensor will be almost equivalent, i.e., $\tau_{\text {surf }} \approx \tau_{S A W}$, while these delays are not used for the following processing, which is different from the conventional GPR approach.

For the used SAW sensor, its frequency domain and time domain reflections are shown in Fig. 2. It can be seen that its active working frequency ( $\mathrm{S} 11$ smaller than $-6 \mathrm{~dB}$ ) is from 2.38 to $2.48 \mathrm{GHz}$. Since the sensor has six reflectors (1 start reflector, 3 coded reflector, 1 parity reflector, and 1 stop reflector), $P=6$ echoes with time delay $\tau_{\mathrm{p}}$ from $1 \mu$ s to $3 \mu$ s can be observed from the right sub-figure of Fig. 2. We will use these peaks to measure the temperature change. The delays with micro-second (hundreds-meters) scale can help to distinguish the sensor echoes from the surrounding reflections. Therefore, the phase change of surrounding reflections will not influence the phase of the sensor, i.e., the measured phase change is only related to concrete properties, which is an advantage of the proposed method over conventional methods.

As the $\mathrm{YX} 1 / 128^{\circ}$ lithium niobate piezoelectric substrate of the used SAW sensor has high sensitivity to temperature and insensitivity to moisture and pressure, the delay $\tau_{p}$ will be changed along with the temperature variation of the concrete, which causes phase difference of different echoes. For example, at time $t_{m}$ with temperature $T^{m}$, the phase difference of the $p$-th and $q$-th echoes $(1 \leqslant p \neq q \leqslant 6)$ are given by

$$
\varphi_{p, q}^{m}=\varphi_{p}^{m}-\varphi_{q}^{m}=2 \pi f_{c}\left[\tau_{p}^{m}+\tau_{S A W}^{m}-\tau_{q}^{m}-\tau_{S A W}^{m}\right]=2 \pi f_{c}\left[\tau_{p}^{m}-\tau_{q}^{m}\right](1)
$$

which is independent from the delay $\tau_{S A W}$ that may be changed by the permittivity of the concrete. Then, at $t_{n}$ with temperature $T^{n}$, the phase difference can be expressed as

$$
\varphi_{p, q}^{n}=\varphi_{p}^{n}-\varphi_{p}^{n}=2 \pi f_{c}\left[\tau_{p}^{n}-\tau_{q}^{n}\right]
$$

where $f_{c}$ is center frequency. Therefore, the temperature change can be measured by the differential interferometric process by calculating the phase difference between two measurements at different time, as given by

$$
\Delta \varphi_{p, q}^{m, n}=\varphi_{p, q}^{m}-\varphi_{p, q}^{n}=2 \pi f_{c}\left[\left(\tau_{p}^{m}-\tau_{q}^{m}\right)-\left(\tau_{p}^{n}-\tau_{q}^{n}\right)\right]
$$

Given the temperature sensitivity of the lithium niobate piezoelectric substrate as $S(70 \mathrm{ppm} / K)$, the temperature change can be estimated based on the phase difference as [14]

$$
\Delta T^{m, n}=T^{m}-T^{n}=\Delta \varphi_{p, q}^{m, n} /\left(2 \pi f_{c} \Delta \tau_{p, q} S\right)
$$

where $\Delta \tau_{p, q}$ is the time delay between the $p$-th and $q$-th echoes.

\section{COMPACT MONOPOLE ANTENNA DESIGN}

The SAW sensor used for concrete wall monitoring requires an antenna with a compact size, due to the fact that it must be buried inside the concrete wall. If a too large antenna were mounted into the concrete wall, the structure strength would be deteriorated. Patch antenna is a good candidate for this application because of its compact size and ease of fabrication. In this study, a compact monopole patch antenna is designed and tested. The configuration evolution of the proposed antenna is shown in Fig. 3. A traditional monopole antenna in Fig. 3(a) has been firstly designed on a 1.6-mm-thickness FR-4 substrate ( $\varepsilon_{r}=4.2$ and $\tan \delta=0.002$ ) with a size of $27 \mathrm{~mm} \times 12 \mathrm{~mm}$. In order to broaden the working band and decrease the insertion loss, a coplanar waveguide (CPW) feed is utilized to connect the monopole patch to the SAW sensor. To improve the bandwidth as well as make the antenna more compact, the corrugated edge, as shown in Fig. 3(b), is proposed. Corrugated edge is a frequently-used method to compensate for the effect of size reduction on the performance of antennas at low frequencies. By adding slots to the radiating edge of an antenna, the electrical length of the structure can be increased as each slot presents an inductive reactance to the passing waves [15]. Therefore, the corrugated radiator resonates at a lower frequency, as compared with a non-corrugated structure of the same dimensions. In addition, corrugated edge does not damage the symmetry of the structure, and its parameters are easy to adjust, which means that corrugated edge is very suitable to work together with the half-cut technique for further miniaturization. 


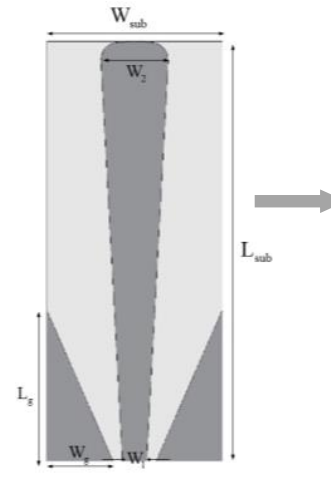

(a)

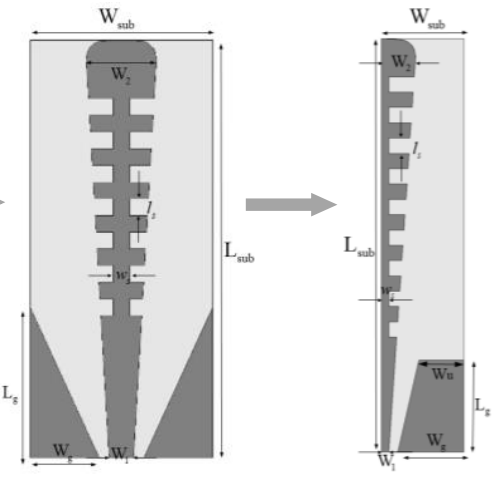

(b)

(c)
Fig. 3. Evolution of the proposed antenna configuration. (a) Original monopole antenna; (b) Modified monopole antenna with corrugated edges; (c) Half-cut monopole antenna with corrugated edges.

Table I. GEOMETRICAL PARAMETERS OF THE OPTIMIZED HALF-CUT ANTENNA

\begin{tabular}{cccc}
\hline Parameter & Value $(\mathbf{m m})$ & Parameter & Value $(\mathbf{m m})$ \\
\hline $\mathbf{W}_{\text {sub }}$ & 5.5 & $\mathbf{L}_{\text {sub }}$ & 27 \\
$\mathbf{W}_{\mathbf{1}}$ & 0.5 & $\mathbf{W}_{\mathbf{2}}$ & 2.28 \\
$\mathbf{W}_{\mathbf{g}}$ & 4.4 & $\mathbf{L}_{\mathrm{g}}$ & 6 \\
$\mathbf{W}_{\mathbf{s}}$ & 0.5 & $\mathbf{l}_{\mathbf{s}}$ & 1 \\
$\mathbf{W}_{\mathbf{u}}$ & 3.4 & & \\
\hline
\end{tabular}

Owing to the symmetry of the monopole antenna structure, the half structure technique is able to be used to further decrease the antenna size. The physical mechanism of the half structure technique is that the current distribution is symmetrical along the line of symmetry of the full antenna, and removing half of the patch does not appreciably affect the current paths and hence the resonant behavior of the structures [16]. The key point of the half structure is to keep the current distribution as same as its full structure. Traditionally, shorting wall or shorting pins are applied to achieve this aim [17-18]. However, in this study, we alter the parameters of the CPW (especially the ground length $\mathrm{Lg}$ and the upper edge width $\mathrm{W}_{\mathrm{u}}$ ) and the corrugated edge, as shown in Fig. 3(c), to maintain the antenna performance.

As we have learned from Fig. 2, the operation band of the SAW sensor is from 2.38 to $2.48 \mathrm{GHz}$. Note that the permittivity of the concrete is high especially when it is in the hardening and setting process, the working band of the proposed antenna is designed slightly higher than that of the SAW sensor in case that the working band will be shifted to a lower frequency as the antenna is embedded in a high permittivity material. The full-wave electromagnetic models of these three types of antennas have been developed based on the finite -difference time domain (FDTD) approach. The geometry of the proposed antennas has been optimized by a parameter study associated with the dimension of each element forming the antenna; the objective is to obtain the best antenna performance after the full structure is half cut.

Fig. 4 shows the simulated S11 curves of different $\mathrm{Lg}$ when the other structure parameters of the half-cut antenna are fixed. It is observed that the S11 curves are significantly affected by the variation of $\mathrm{Lg}_{\mathrm{g}}$. The return loss becomes better as $\mathrm{Lg}_{\mathrm{g}}$ increases and the antenna get the best working performance when $\mathrm{Lg}_{\mathrm{g}}$ is around $6 \mathrm{~mm}$. Similarly, the influence of the width $\mathrm{W}_{\mathrm{u}}$ is studied and plotted in Fig. 5. $\mathrm{W}_{\mathrm{u}}$ is the width of the upper edge of the ground patch, which determines the gap between the radiation patch and the ground. As seen, by increasing $\mathrm{W}_{\mathrm{u}}$, the operation band gradually increases, indicating that a small gap will increase the working performance of the antenna. Therefore, by altering the structure parameters, especially the parameters of the CPW and the corrugated edge, the working performance of the monopole antenna could be maintained. After extensive simulations, the geometry of the proposed half-cut monopole antenna is optimized and all geometrical parameters are list in Table I. Comparing to other miniaturization methods such as fractal-based method, half-cut monopole antenna with corrugated edge is suitable to our cooperative target since its structure width is extremely small and its feeding structure meets well with our SAW sensor.

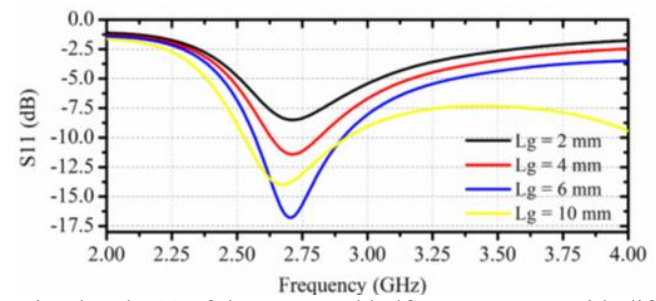

Fig. 4. Simulated S11 of the proposed half-cut structure with different Lg.

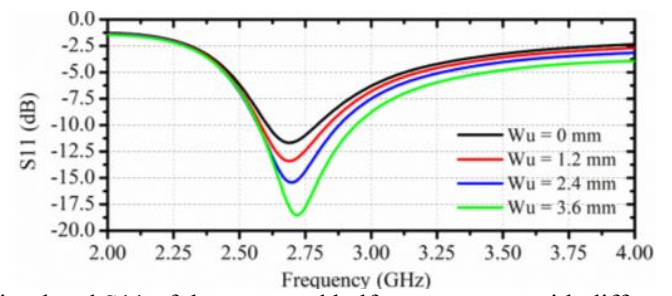

Fig. 5. Simulated S11 of the proposed half-cut structure with different $\mathrm{W}_{\mathrm{u}}$.

Fig. 6 illustrates the simulated reflection coefficient variations of the three optimized monopole antenna structures. It can be seen that the operation band of the original monopole antenna with $\mathrm{S} 11$ less than $-10 \mathrm{~dB}$ is ranged from 2.74 to 3.38 $\mathrm{GHz}$. By adding the corrugated edges to the original antenna, the S11 curve shifts significantly to lower frequency band and the lowest working frequency is around $2.54 \mathrm{GHz}$, indicating that the size of the antenna is decreased by $10 \%$ regarding the same working frequency. It is also observed that the operation band of the half-cut monopole antenna is almost same with its full structure except the frequency band higher than $2.9 \mathrm{GHz}$. Note that the mainly used frequency band is ranged from 2.6 to $2.8 \mathrm{GHz}$ (considering the frequency shift in the concrete), this difference is within an acceptable level. In other words, by utilizing the half structure technique, the size of the proposed antenna is reduced by $50 \%$ compared to its original size without sacrificing the antenna performance. The similar current distribution of the two structures at $2.7 \mathrm{GHz}$ also confirms this statement, which is shown in the inset in Fig 6. The simulated reflection coefficient of the half cut structure in the concrete at early age ( $\varepsilon_{r}=11.2$ and $\tan \delta=0.2$ ) is also plotted in Fig. 6 by 
the dash line. It shows that the operation band of the antenna shifts to lower band from $2.58-2.9 \mathrm{GHz}$ to $2.35-2.75 \mathrm{GHz}$ after embedding the antenna inside concrete. The shifted operation band matches well with that of the SAW sensor, which indicates that the antenna is able to work with the SAW sensor inside the concrete wall.

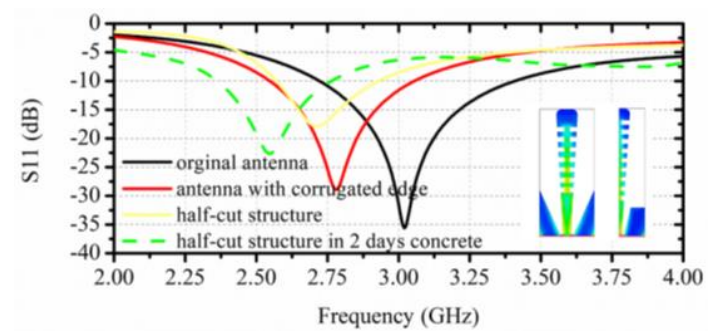

Fig. 6. Simulated S11 of the three monopole antenna structures.

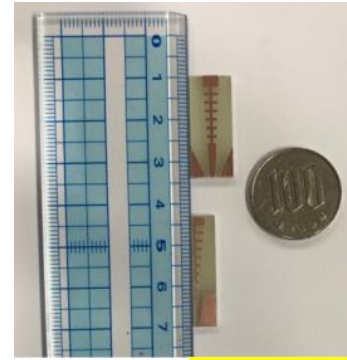

(a)

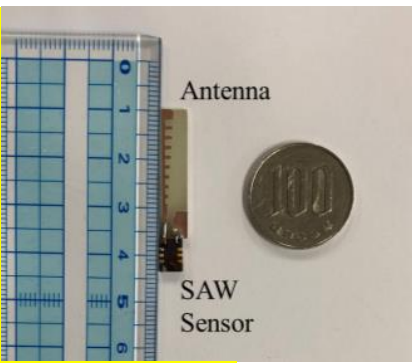

(b)
Fig. 7. Fabricated antennas. (a) Photograph of the fabricated half-cut monopole antenna and its full structure; (b) Photograph of the fabricated half-cut monopole antenna connected to the SAW sensor.

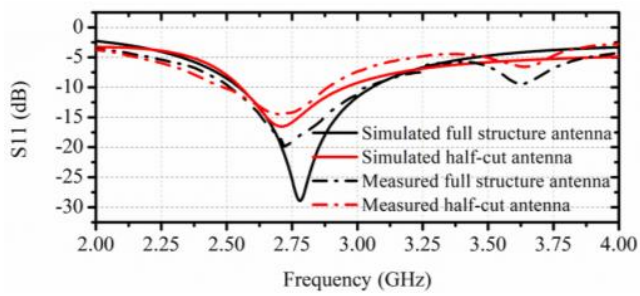

Fig. 8. Measured and Simulated S11 of the half-cut monopole antenna and its full structure.

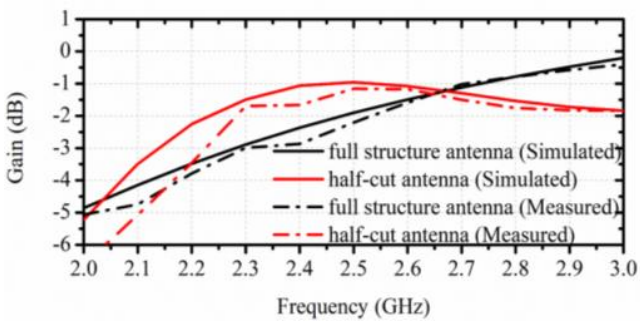

Fig. 9. Measured and Simulated Gain of the half-cut monopole antenna and its full structure.

The proposed half-cut monopole antenna and its full structure are fabricated and tested as shown in Fig. 7. All geometrical parameters of the fabricated antenna are listed in Table I. Fig. 8 shows the simulated and measured return loss of the two antenna structures against different frequencies. The result is obtained by an Agilent E5071C VNA and the influence of coaxial line is eliminated by calibration. The measured operating bands of the two structures with return loss less than $-10 \mathrm{~dB}$ are in good agreement with the simulated ones. The working band of the half-cut monopole antenna is ranged from 2.5 to $2.81 \mathrm{GHz}$, which indicates it is suitable to work with the SAW sensor inside the concrete. The discrepancies between the simulated and measured results might be caused by soldering effect, surface roughness, and other factors, which are difficult to predict.

The measured gain of the two antenna structures is obtained by the standard two-antenna method, as shown in Fig. 9. It can be seen that the measurement results meet well with the simulation results. The gain of the half-cut antenna increases as frequency rises and gets a maximum value of $-1.5 \mathrm{dBi}$ at the frequency of $2.55 \mathrm{GHz}$. In the frequency band from 2.15 to 2.65 $\mathrm{GHz}$, the gain of the half-cut antenna is higher than its full structure, and, in the frequency band from 2.65 to $3 \mathrm{GHz}$, the full antenna structure gives a higher gain performance due to its wider operation band. Considering the compact size and omnidirectional radiation pattern, the gain of the proposed monopole antenna is acceptable.

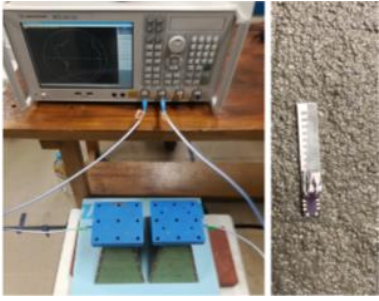

(a)

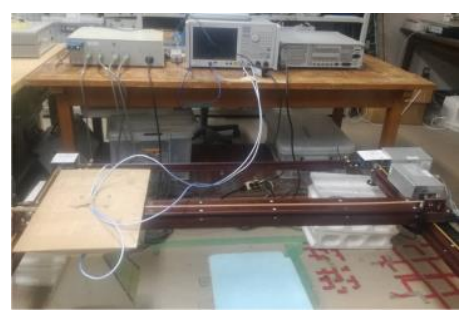

(b)
Fig. 10. Experiment setups. (a) Temperature change monitoring; (b) Synthetic aperture measurement.

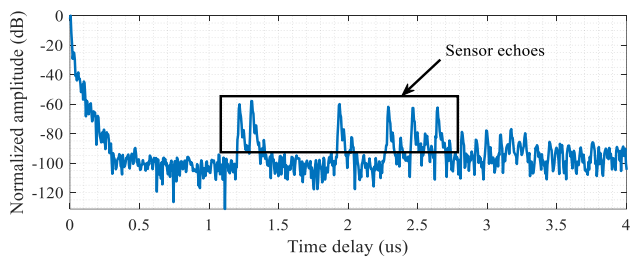

Fig. 11. Range compression result: six echoes of the sensor are clear.

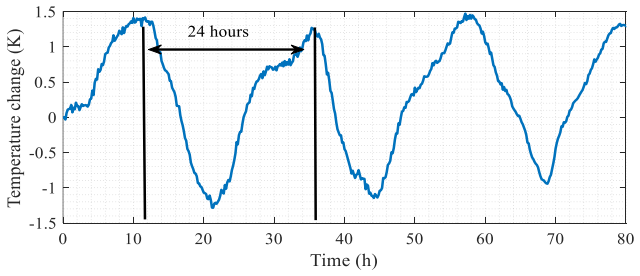

Fig. 12. Temperature changes for a 80 -hours measurement.

\section{EXPERIMENTAL RESULTS}

To validate the designed antenna, two experiments were conducted. In the first experiment, the sensor was buried in the concrete and its echoes were monitored for 80 hours with a time interval of 10 minutes, as shown in Fig. 10(a). The range compression result is shown in Fig. 11, from which it can be seen that, although antenna mutual-coupling and surrounding reflections are much stronger, the sensor echoes can be clearly observed. Then, by doing the interferometric process for the phase difference of echo 6 and echo 1, the temperature change can be derived, as shown in Fig. 12. The reason to use echo 6 
and echo 1 is that their delay difference is biggest, resulting in high temperature estimation accuracy. It can be seen that the temperature change has a period of about 24 hours, which is corresponded to the practice. It should be noted that, in the current implementation, for simplicity, horn antennas are used to transmit the signal and receive the echoes. Thus, polarization match is needed in order to more easily detect and measure the SAW echoes. Circular polarized antennas can be used to avoid this requirement. In such a case, the link budget of the SAW sensor will not be influenced too much by the relative antenna orientations. As shown in Fig. 11, the SNR of the sensor echoes is high enough to tolerate the potential SNR loss.

To further validate the designed antenna for SAW sensor application with different incident angles, the measurement antennas are mounted on a positioner to generate a synthetic aperture to determine the angle of the sensor, as shown in Fig. 10(b), where the synthetic aperture is $80 \mathrm{~cm}$ and the antenna moving step is $10 \mathrm{~cm}$. The range compression results for all antennas positions are shown in Fig. 13 with a dynamic range of $40 \mathrm{~dB}$. As we can see, the six echoes can be clearly observed for all antenna positions. When the antenna is moved away from the sensor, the sensor echo strength is reduced, which is caused by the directivity of the used horn antenna. At last, by using the azimuth compression method proposed in [14], the angle of the sensor can be determined, as shown in Fig. 14, where the sensor is located at about $6.5^{\circ}$.

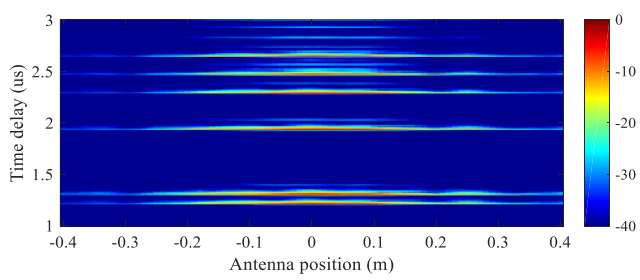

Fig.13. Range profiles for all antenna positions.

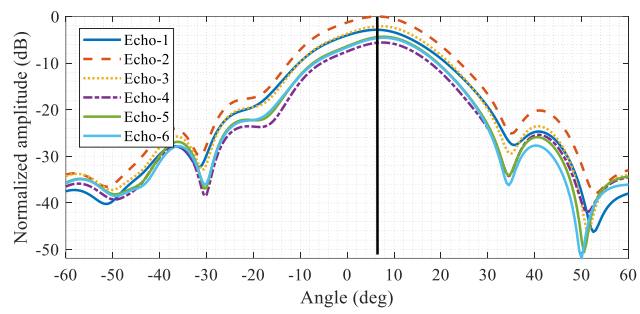

Fig.14. Sensor azimuth angle determination result.

\section{CONCLUSION}

Practical considerations for utilizing half-cut monopole antenna with SAW sensor as cooperative target to monitor the temperature of concrete wall have been investigated. Taking the advantages of corrugated edge and half-structure technique, the size of the proposed monopole antenna has been decreased significantly, making the cooperative target suitable to be inserted into the concrete or mounted on the steel rebar. The experimental results show that the proposed antenna works well with the SAW sensor inside concrete and can monitor the temperature change continuously. In addition, the location of the cooperative target can also be detected, which indicates the temperature distribution of the whole concrete structure can be obtained when multiple cooperative sensors are inserted at different positions. Compared to traditional techniques, as the cooperative target is a passive device, the monitoring could theoretically be able to last for a life-long time.

\section{REFERENCES}

[1] P.C. Chang, A. Flatau, and S.C. Liu, "Health monitoring of civil infrastructure," Structural Health Monitoring, vol. 2, no. 3, pp. 257-267, Sep. 2003.

[2] P. Rizzo, X. Ni, S. Nassiri, and J. Vandenbossche, "A Solitary Wave-Based Sensor to Monitor the Setting of Fresh Concrete," Sensors, vol. 14, no. 7, pp. 12568-12584, Jul. 2014.

[3] A. M. Neville, "Strength of concrete," in Properties of Concrete, 5th ed., UK: Pearson Education Ltd, 2011, ch.6, pp. 906-1050.

[4] Z. Sun, T. Voigt, and S. P. Shah, "Temperature effects on strength evaluation of cement-based materials with ultrasonic wave reflection technique," ACI Mater. J., vol. 102, no. 4, pp. 272-278, Jul. 2015.

[5] T. Voigt, C.U. Grosse, Z. Sun, S. P. Shah, and H. W. Reinhardt, "Comparison of ultrasonic wave transmission and reflection measurements with P- and S-waves on early age mortar and concrete," Mater. Struct., vol. 38, no. 8, pp. 729-738, Jan. 2005.

[6] A. Norris, M. Saafi, and P. Romine, "Temperature and moisture monitoring in concrete structures using embedded nanotechnology /microelectromechanical systems (MEMS) sensors," Constr. Build. Mater., vol. 22, pp. 111-120, 2008.

[7] H. Gu, G. Song, H. Dhonde, Y. L. Mo, and S. Yan, "Concrete early-age strength monitoring using embedded piezoelectric transducers," Smart Mater. Struct., vol. 15, no.6, pp. 1837-1845, Nov. 2006.

[8] G. Grandjean, J. C. Gourry, and A. Bitri, "Evaluation of GPR techniques for civil-engineering applications: Study on a test site," J. Appl. Geophys., vol. 45, no. 3, pp. 141-156, Oct. 2000.

[9] F. Soldovieri, R. Solimene, L. Monte, M. Bavusi, M. and A. Loperte, "Sparse reconstruction from GPR data with applications to rebar detection," IEEE transactions on instrumentation and measurement, vol. 60, no. 3, pp.1070-1079, 2011.

[10] J. Kim, R. Luis, M. Smith, J. Figueroa, D. C. Malocha, B. H. Nam, "Concrete temperature monitoring using passive wireless surface acoustic wave sensor system," Sensors and Actuators A: Physical, vol. 224, pp. 131-139, Apr. 2015.

[11] J.-M. Friedt, et al., "Acoustic transducers as passive cooperative targets for wireless sensing of the sub-surface world: challenges of probing with ground penetrating RADAR," Sensors, vol. 18, no. 1, 246, 2018.

[12] J.-M. Friedt, "Passive cooperative targets for subsurface physical and chemical measurements: a systems perspective," IEEE Geoscience and Remote Sensing Letters, vol. 14, no. 6, pp. 821-825, 2017.

[13] W. Feng, J.-M. Friedt, Z. Hu, G. Cherniak, and M. Sato, "Wifi based imaging for gpr applications: fundamental study and experimental results," in IET international radar conference 2018, 2018, pp. 1-5.

[14] W. Feng, J.-M. Friedt, G.-M. Gwenhael, and M. Sato, "Passive radar delay and angle of arrival measurements of multiple acoustic delay lines used as passive sensors," IEEE Sensors Journal, vol. 19, no. 2, pp. 594-602, 2018.

[15] T. Milligan, Modern Antenna Design, 2nd ed. Piscataway, NJ: IEEE Press, 2005.

[16] R. Chair et al., "Miniature wide-band half U-slot and half E-shaped patch antennas," IEEE Trans. Antennas Propag., vol. 53, no. 8, pp. 2645-2652, Aug. 2005.

[17] S. Pinhas, and S. Shtrikman, "Comparison between computed and measured bandwidth of quarter-wave microstrip radiators," IEEE Trans. Antennas Propag., vol. 36, pp. 1615-1616, Nov. 1988.

[18] R. B. Waterhouse, "Small microstrip patch antenna," Electron. Lett., vol.31, pp. 604-605, 1995.

[19] S. Yehia, N. Qaddoumi, S. Farrag, and L. Hamzeh, "Investigation of concrete mix variations and environmental conditions on defect detection ability using GPR,” NDT E Int., vol. 65, pp. 35-46, Jul. 2014. 